\title{
Optimal Timing of Preoperative Skin Preparation with Povidone-Iodine for Spine Surgery: A Prospective, Randomized Controlled Study
}

\author{
Tatsuya Yasuda, Tomohiko Hasegawa, Yu Yamato, Sho Kobayashi, \\ Daisuke Togawa, Hideyuki Arima, Yukihiro Matsuyama \\ Department of Orthopaedic Surgery, Hamamatsu University School of Medicine, Hamamatsu, Japan
}

\begin{abstract}
Study Design: A prospective, randomized, controlled study.
Purpose: The objective of this study was to evaluate the effectiveness of two techniques of skin preparation with povidone-iodine. Overview of Literature: Preoperative skin preparation is important for preventing surgical site infection by reducing the bacteria in the surgical area. Povidone-iodine is a commonly used agent for preoperative skin preparation, and further decrease in surgical site infections can be expected by understanding how to apply it more effectively.

Methods: Eighty-nine spine surgery patients were randomly allocated to two groups. In group A, povidone-iodine was applied to the surgical site just before starting the operation; in group B, povidone-iodine was applied several minutes prior to starting the operation and was allowed to dry. We collected samples from the wound edge before suturing, and we compared the rates of positive culture between the two groups.

Results: The rate of positive culture was 30.2\% (13 out of 43 patients) in group A, and $6.5 \%$ (3 out of 46 patients) in group B. This indicates that there was a significant difference in postoperative infection rates between group $A$ and group $B$.

Conclusions: Because bacteria on the skin appeared significantly reduced by allowing povidone-iodine to dry for several minutes prior to surgery, we recommend this approach to reduce the incidence of postoperative infections.
\end{abstract}

Keywords: Surgical wound; Infection; Povidone-iodine

\section{Introduction}

Surgical site infection (SSI) is a common complication after spinal surgery. Despite the use of prophylactic antibiotics, advances in surgical techniques and postoperative care, clinical results of compromised patients show significant morbidity and prolonged hospitalization.

Recently, the surgical indication has been expanded to elderly patients, who are considered to be having a relatively higher risk of surgical infection. Additionally, patients with diabetes and who are on dialysis are at high risk of infection due to immunocompromised status.

The stage of prevention of surgical site infection can be classified in three phases; preoperative, intraoperative, and postoperative. Skin preparation in the preoperative phase is very important for preventing infection, and povidoneiodine is one of the most commonly used agents for this purpose. This study investigated the effectiveness of two

Received Oct 8, 2014; Revised Nov 18, 2014; Accepted Nov 25, 2014

Corresponding author: Tatsuya Yasuda

Department of Orthopaedic Surgery, Hamamatsu University of Medicine,

1-20-1 Handayama, Higashi-ku, Hamamatsu 431-3192, Japan

Tel: +81-53-435-2299, Fax: +81-53-435-2296, E-mail: t.yasuda@hama-med.ac.jp 
different timings of skin preparation with povidoneiodine.

\section{Materials and Methods}

In this prospective study, 89 consecutive patients scheduled for spinal surgery between March 2010 and September, 2010 were randomly allocated to 2 groups according to the patient identification numbers with their consent. Forty-three patients were included in group A and 46 patients were included in group $\mathrm{B}$. The average patient age was 61.9 years in group A (range, 18-86 years) and 58.1 years in group B (range, 14-82 years). The average operating time was 230 minutes in group $A$ and 216 minutes in group B, respectively. Cervical surgery was performed in 17 patients (39.5\%) of group A and 15 patients (32.6\%) of group B. Instrumentation surgery was performed in 25 patients (58.1\%) of group A and 24 patients (52.2\%) of group B (Table 1).

In group A, povidone-iodine was applied to the surgical site just before the skin incision, after the surgeon's hands were scrubbed. In group B, povidone-iodine was applied before the surgeon's hands were scrubbed. Therefore, there was an interval of at least five minutes, enough time for drying povidone-iodine, before skin incision compared to povidone-iodine application in group A. In all cases, the surgical field was sealed with an antimicrobial plastic adhesive wound drape just before starting the surgery.

Culture samples were collected by rubbing a cotton swab at the wound edge just before wound closure and then they were incubated at $37^{\circ} \mathrm{C}$ for 5 to 7 days. Bacteria were identified by means of standard laboratory identification methods.

Cefazolin was administered three times on the day of surgery, before surgery, one hour after surgery, and six hours after surgery, and two times on the next day as a prophylactic antibiotic.

We analyzed the rate of positive bacterial culture in each group. Pearson's $\chi^{2}$ tests were used to compare the positive culture rate between the two groups. The level of significance was set at $p<0.01$.

\section{Results}

The positive culture rate was $30.2 \%$ (13 out of 43 patients) in group A and $6.5 \%$ (3 out of 46 patients) in group B (Table 2), and it was significantly different between group
Table 1. Patient demographics in each group

\begin{tabular}{lcc} 
Characteristic & Group A & Group B \\
\hline No. of patients & 43 & 46 \\
\hline Average age (yr) & 61.9 & 58.1 \\
Male:female & $21: 22$ & $23: 23$ \\
\hline Average operating time & 230 & 216 \\
\hline Surgical level & & \\
$\quad$ Cervical & 17 & 15 \\
\hline$\quad$ Thoracolumbar & 26 & 31 \\
\hline Instrumentation surgery & 25 & 24 \\
\hline
\end{tabular}

Table 2. Culture results

\begin{tabular}{lcc} 
Culture & Group A & Group B \\
Positive & 13 & 3 \\
Negative & 30 & 43 \\
\hline$p=0.004$ & &
\end{tabular}

Table 3. Bacterial species

\begin{tabular}{lcc} 
Bacterial species & Group A & Group B \\
Coagulase-negative staphylococci & 12 & 1 \\
$\begin{array}{l}\text { Methicillin-sensitive Staphylococcus } \\
\text { aureus }\end{array}$ & 1 & - \\
$\gamma$ Streptococcus & - & 1 \\
Staphylococcus epidermidis & - & 1 \\
\hline
\end{tabular}

A and group B ( $p=0.004)$. In group A, coagulase negative Staphylococcus was identified in 12 cultures and methicillin-sensitive Staphylococcus aureus was identified in 1 culture. In group B, three different bacteria ( $\gamma$ Streptococcus, staphylococcus epidermidis, and coagulase negative Staphylococcus) were identified in the culture, respectively (Table 3). Two cases of SSI (deep infection) (2 out of 46 patients, $4.3 \%$ ) were identified in group B four weeks after surgery, and cultures from the wound edge intraoperatively were negative. There was no case of SSI in group A after the surgery.

\section{Discussion}

SSI following adult spinal surgery is a common complication that has been reported to occur in $0.7 \%$ to $12.0 \%$ [1-10] of patients, and it results in higher postoperative 
morbidity, mortality, and increased health care costs $[1,11,12]$. Recently, the surgical indication has been expanded to elderly patients; hence, the chances of spinal surgery in immunocompromised patients have increased. In particular, cases of spinal instrumentation surgery are comparatively difficult to treat when they get infected [13]; thus, prevention of infection is very important for spinal surgery.

The prevention of SSI can be classified into the preoperative, intraoperative, and postoperative phases. The preoperative phase includes diabetes control, shorter hospital stay before surgery, etc. Also, it is important to check the preoperative colonization status, for example, the history of dental treatment. Techniques for prevention of SSI during the operation commonly include the use of a clean room, appropriate antibiotic use, and maintenance of clean surgical fields. Finally, good nutrition and proper wound care are important factors in postoperative prevention of SSI. In this study, the two cases of SSI (deep infection) found in group B were of postoperative phase infections since they occurred four weeks after surgery, and the cultures from the wound edge intraoperatively were negative.

Preoperative skin preparation is necessary for the prevention of SSI in the intraoperative phase. In the intraoperative phase, a key factor for preventing infection is the elimination of bacterial contamination of the surgical site at the time of surgery [14-18]. The purpose of preoperative skin preparation is to reduce bacteria on the skin. In this study, the positive culture rate in group A was significantly higher than that in group B. Thus, the method used in group B was more effective in the intraoperative phase.

Although variation exists in timings and techniques for skin preparation before surgery, one of the most commonly used techniques involves painting the surgical field with povidone-iodine [12-16]. Povidone-iodine is a bactericidal agent effective against a wide spectrum of pathogens. The preventive effect of povidone-iodine on SSI has been reported to be equivalent to that of other antiseptic agents [2,4]. Moen et al. [13] reported the number of bacterial colonies after spraying povidone-iodine 1 minute before and 3 minutes before performing abdominal wall surgery. They reported that spraying povidone-iodine 3 minutes before was more effective in reducing bacterial counts than spraying povidone-iodine 1 minute before surgery. Additionally, the results of this study suggested that povidone-iodine was more effective when it was al- lowed to dry for 10 minutes prior to surgery. Additionally, if the drape was used in a wet condition, it was possible that the effect of the shield was insufficient. We recommend allowing 10 minutes drying time after povidoneiodine painting of the surgical field for preoperative preparation.

A limitation of this study is that only analysis of cultures from the wound edge was conducted. Also, the plastic adhesive wound drape was peeled easily in group A since the surgical field was not dry when it was applied. Plastic shielding may have also been associated with culture results. Another limitation is the lack of patient background data, especially the risk factors for infection. Nevertheless, the purpose of preoperative skin preparation is to reduce bacteria in the surgical field and to reduce the incidence of SSI. Therefore, allowing 10 minutes drying time after povidone-iodine painting of the surgical field is a simple step in preoperative skin preparation that may reduce the rate of SSI, thus resulting in reducing length of the hospital stay and costs incurred by the patient.

\section{Conclusions}

We evaluated the effectiveness of two techniques of skin preparation with povidone-iodine. Because bacteria on the skin appeared significantly reduced by allowing povidone-iodine to dry for 10 minutes prior to surgery, we recommend this approach to reduce the incidence of postoperative infections.

\section{Conflict of Interest}

No potential conflict of interest relevant to this article was reported.

\section{References}

1. Abbey DM, Turner DM, Warson JS, Wirt TC, Scalley RD. Treatment of postoperative wound infections following spinal fusion with instrumentation. J Spinal Disord 1995;8:278-83.

2. Charehbili A, Swijnenburg RJ, van de Velde C, van den Bremer J, van Gijn W. A retrospective analysis of surgical site infections after chlorhexidine-alcohol versus iodine-alcohol for pre-operative antisepsis. Surg Infect (Larchmt) 2014;15:310-3.

3. Darouiche RO, Wall MJ Jr, Itani KM, et al. Chlorhex- 
idine-alcohol versus povidone-iodine for surgicalsite antisepsis. N Engl J Med 2010;362:18-26.

4. Glassman SD, Dimar JR, Puno RM, Johnson JR. Salvage of instrumental lumbar fusions complicated by surgical wound infection. Spine (Phila Pa 1976) 1996;21:2163-9.

5. Guzel A, Ozekinci T, Ozkan U, Celik Y, Ceviz A, Belen D. Evaluation of the skin flora after chlorhexidine and povidone-iodine preparation in neurosurgical practice. Surg Neurol 2009;71:207-10.

6. Hakkarainen TW, Dellinger EP, Evans HL, et al. Comparative effectiveness of skin antiseptic agents in reducing surgical site infections: a report from the Washington State Surgical Care and Outcomes Assessment Program. J Am Coll Surg 2014;218:336-44.

7. Hemani ML, Lepor H. Skin preparation for the prevention of surgical site infection: which agent is best? Rev Urol 2009;11:190-5.

8. Jarral OA, McCormack DJ, Ibrahim S, Shipolini AR. Should surgeons scrub with chlorhexidine or iodine prior to surgery? Interact Cardiovasc Thorac Surg 2011;12:1017-21.

9. Keller RB, Pappas AM. Infection after spinal fusion using internal fixation instrumentation. Orthop Clin North Am 1972;3:99-111.

10. Kostuik JP, Israel J, Hall JE. Scoliosis surgery in adults. Clin Orthop Relat Res 1973;(93):225-34.

11. Lonstein J, Winter R, Moe J, Gaines D. Wound infection with Harrington instrumentation and spine fusion for scoliosis. Clin Orthop Relat Res 1973; (96):222-33.

12. Mears SC, Dinah AF, Knight TA, Frassica FJ, Belkoff SM. Visibility of surgical site marking after preoperative skin preparation. Eplasty 2008;8:e35.

13. Moen MD, Noone MB, Kirson I. Povidone-iodine spray technique versus traditional scrub-paint technique for preoperative abdominal wall preparation. Am J Obstet Gynecol 2002;187:1434-6.

14. Mok JM, Guillaume TJ, Talu U, et al. Clinical outcome of deep wound infection after instrumented posterior spinal fusion: a matched cohort analysis. Spine (Phila Pa 1976) 2009;34:578-83.

15. Olsen MA, Mayfield J, Lauryssen C, et al. Risk factors for surgical site infection in spinal surgery. J Neurosurg 2003;98:149-55.

16. Pull ter Gunne AF, Mohamed AS, Skolasky RL, van Laarhoven CJ, Cohen DB. The presentation, incidence, etiology, and treatment of surgical site infections after spinal surgery. Spine (Phila Pa 1976) 2010;35:1323-8.

17. Roberts FJ, Walsh A, Wing P, Dvorak M, Schweigel $J$. The influence of surveillance methods on surgical wound infection rates in a tertiary care spinal surgery service. Spine (Phila Pa 1976) 1998;23:366-70.

18. West JL 3rd, Ogilvie JW, Bradford DS. Complications of the variable screw plate pedicle screw fixation. Spine (Phila Pa 1976) 1991;16:576-9. 